\title{
Radiogenic isotopes: A versatile toolkit for understanding the convecting mantle
}

\section{LAURIE REISBERG}

Université de Lorraine, CNRS, CRPG

Presenting Author: laurie.reisberg@univ-lorraine.fr

Radiogenic isotopes have been used for over 40 years to constrain the dynamics of the Earth's convecting mantle. Early studies of $\mathrm{Sr}, \mathrm{Nd}$ and $\mathrm{Pb}$ isotopes [1] showed that mid-ocean ridge basalts (MORB) derive from a relatively homogeneous reservoir, depleted in incompatible elements by extraction of the continental crust. Isotope compositions of ocean island basalts (OIB) indicate less incompatible element depletion and considerably more diversity in their sources. Zindler and Hart [2] demonstrated that this diversity was defined by a limited number of components, including a prevalent component present in most OIB sources. Additional data, and inclusion of Hf isotopes in the toolkit, expanded on and refined this view of the oceanic basalt database [3]. Most of the observed heterogeneity can be explained by return to the convecting mantle of surficial material, including altered oceanic crust, sediments, and continental crustal material, through subduction or possibly lithospheric delamination.

Nevertheless this vision, obtained essentially from basalts, is inherently biased by the melt generation process. Direct samples of the convecting mantle, abyssal and ophiolitic peridotites, are difficult to study with incompatible isotopes, but can be addressed using isotopes of Os, a highly compatible element. Os isotopes have shown that some abyssal peridotites have highly depleted compositions that have resisted homogenization by convection for nearly 2 Gy. Furthermore, abyssal peridotite Os isotope compositions are on average less radiogenic than those of MORB, implying the widespread presence of enriched components in the MORB source.

While reincorporation of enriched material on both large and small scales can explain much of the observed isotopic heterogeneity, this is not the full story. Compositional heterogeneity may have been inherited from Earth's accretion or from early magma ocean differentiation. Such processes can be addressed using isotopes, such as ${ }^{182} \mathrm{~W}$, produced by extinct radio-nuclides. Recent ${ }^{182} \mathrm{~W}$ studies have produced exciting results, including intriguing evidence for a contribution from the Earth's core to some OIB sources [4].

[1] Allegre (1982), Tectonophysics 81, 109-132

[2] Zindler \& Hart (1986), Ann. Rev. Earth Planet. Sci. 14, 493-571.

[3] Stracke (2012), Chemical Geology 330-331, 274-299.

[4] Rizo et al. (2019), Geochem. Persp. Lett. 11, 6-11. 